\title{
EVALUASI USER EXPERIENCE GAME 2D BAJAJ KELILING MENGGUNAKAN METODE GAME EXPERIENCE QUESTIONNAIRE
}

\author{
Nike Joncicilia, Riwinoto \\ * Informatics Engineering, Batam State Polytechnic \\ ** Multimedia and Network Engineering, Batam State Polytechnic
}

\begin{tabular}{l}
\hline Article Info \\
\hline Article history: \\
Received Oct $12^{\text {th }}, 2020$ \\
Revised Nov $20^{\text {th }}, 2020$ \\
Accepted Dec $16^{\text {th }}, 2020$ \\
\hline
\end{tabular}

\section{Keyword:}

Bajaj Keliling

Game

Game Experience Questionnaire User Experience

\begin{abstract}
Di era digital ini, permainan smartphone menjadi populer bagi semua kalangan. Meskipun jumlah gamers di Indonesia semakin meningkat, tidak menjamin bahwa setiap game memiliki jumlah peminat yang banyak. Setiap industri game berlomba-lomba untuk memiliki user experience yang baik agar para peminat game industri tersebut selalu meningkat. Ini menunjukkan bahwa user experience pada sebuah game sangat penting untuk mendukung kesuksesan sebuah game. Permainan Bajaj Keliling belum pernah melakukan evaluasi user experience sebelumnya. Untuk keberhasilan permainan Bajaj Keliling, maka dari itu perlu dilakukan evaluasi user experience. Setelah dilakukan evaluasi user experience pada permainan Bajaj Keliling, maka akan dilakukan perancangan ulang berdasarkan rekomendasi evaluasi user experience pertama, lalu hasil perancangan ulang permainan Bajaj Keliling akan dievaluasi kembali. Metode yang digunakan untuk evaluasi menggunakan Game Experience Questionnaire, sedangkan untuk proses perancangan menggunakan metode Design Sprint. Setelah dilakukan analisis pertama, hasil menunjukkan bahwa pada Core Module untuk komponen flow bernilai 2.17 dan challenge bernilai 2.21, serta komponen challenge pada Ingame Module bernilai 2.22, semua nilai rata-rata tersebut rendah dan berada di bawah median. Hal tersebut menunjukkan bahwa permainan mudah untuk dimainkan dan tidak terlalu menantang. Solusi yang diimplementasikan yaitu mengganti fitur stage menjadi level dan menambahkan tantangan baru berupa pertanyaan pada setiap awal level. Setelah dilakukan evaluasi kedua, hasil pada Core Module untuk komponen flow yaitu 3.17 dan challenge yaitu 3,09, rata-rata menjadi meningkat dan berada di atas median. Hasil dari komponen challenge pada In-game Module juga meningkat menjadi 2.37, namun nilai rata-rata tersebut masih di bawah median.
\end{abstract}

Copyright () 2020 Multimedia and Network Engineering. All rights reserved.

\section{Corresponding Author:}

First Author,

Multimedia and Network Engineering,

Batam State Polytechnic,

Jl. Ahmad Yani, Tlk. Kering, Kec. Batam Kota, Kota Batam, Kepulauan Riau, 29461, Indonesia.

Email: joncicilianike@gmail.com

\section{PENDAHULUAN}

Bermain game menjadi kegiatan yang digemari untuk menghilangkan kepenatan dari rutinitas aktivitas, namun bagi sebagian orang game sudah menjadi rutinitas mereka. Perkembangan game dari waktu ke waktu semakin pesat dengan berbagai genre dan jenis perangkat. Di era digital ini, permainan smartphone menjadi populer bagi semua kalangan, perangkat smartphone yang dapat dibawa kemanapun menjadi alasan utama masyarakat memilih permainan smartphone.

Permainan atau game merupakan salah satu media yang berkembang pesat 2 dasawarsa belakangan ini, bahkan mengalahkan laju perkembangan media film keluaran Hollywood. Pada awal 1990-an game masih dianggap hanya untuk anak-anak, di era 2000 ke atas, game telah menjangkau berbagai bidang seperti hiburan untuk kalangan, bisnis, simulasi, edukasi, dan juga pembelajaran virtual [1]. Menurut Fullerton, terdapat 8 elemen formal dalam sebuah permainan, yaitu pemain, tujuan, prosedur, aturan, sumber daya, konflik, batasan, serta hasil dan akibat [2]. 
Hasil studi yang telah dirilis pada Oktober 2018 oleh POKKT, Decision Lab dan Mobile Marketing Association (MMA), gamers di Indonesia telah mencapai 60 juta jiwa dan diperkirakan akan meningkat menjadi 100 juta jiwa di 2020. Dengan banyaknya jumlah penggemar game saat ini, game sangat menjanjikan untuk menjadi sarana edukasi apa saja.

Permainan Bajaj Keliling merupakan permainan 2D platform android rancangan penulis berjenis adventure dengan unsur edukasi tentang daerah-daerah di Indonesia. Setiap pemain diharuskan untuk menyelesaikan perjalanan sampai garis finish agar pemain dapat lanjut ke stage berikutnya. Permainan Bajaj Keliling ini bertujuan untuk memperkenalkan kota-kota di Indonesia kepada siswa SD hingga SMP. Meskipun target usia permainan ini untuk siswa SD hingga SMP, permainan ini tetap bisa dimainkan oleh kalangan orang dewasa.

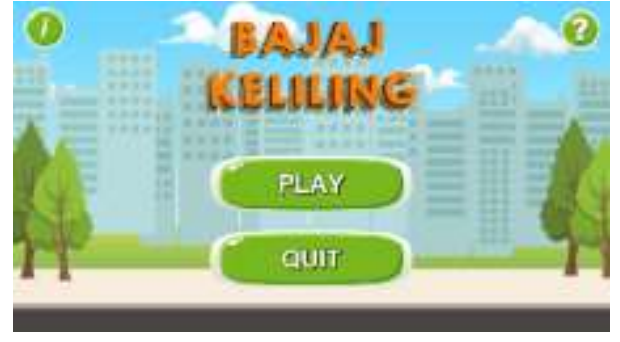

Gambar 1. Tampilan Menu Bajaj Keliling

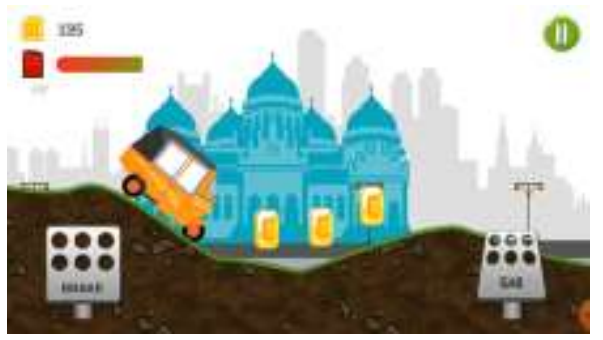

Gambar 2. Tampilan Permainan Bajaj Keliling

Game 2D adalah game yang secara matematis hanya melibatkan 2 elemen koordinat kartesius yaitu x dan y, sehingga konsep kamera pada game 2D hanya menentukan gambar pada game yang dapat dilihat oleh pemain. Menurut Ernest Adams, ada beberapa tampilan permainan 2D, yaitu single screen, side-scrolling, top-scrolling, dan perspektif isometrik [3].

User Experience merupakan nilai-nilai yang dapat diambil dari interaksi yang dialami pengguna suatu produk atau jasa dalam konteks penggunaan tertentu [4]. Keberhasilan atau kesuksesan suatu produk selalu berhubungan dengan hasil pengalaman pengguna terhadap produk tersebut. User experience tidak hanya digunakan untuk permainan saja, user experience juga bisa digunakan oleh produk dan jasa apapun selama mengikuti ketentuan dan prosedur yang berlaku. Meskipun jumlah gamers di Indonesia semakin meningkat, tidak menjamin bahwa setiap game memiliki jumlah peminat yang banyak. Setiap industri game berlomba-lomba untuk memiliki user experience yang baik agar para peminat game industri tersebut selalu meningkat. Ini menunjukkan bahwa user experience pada sebuah game sangat penting untuk mendukung kesuksesan sebuah game.

Permainan Bajaj Keliling belum pernah melakukan evaluasi user experience sebelumnya, sehingga belum diketahui apakah permainan ini layak dipasarkan, sudah cukup baik, atau sudah memenuhi kebutuhan pengguna. Saat pertama kali permainan ini selesai diproduksi, penulis memberikan permainan Bajaj Keliling kepada beberapa orang berusia 20 hingga 22 tahun. Hasilnya menunjukkan bahwa permainan kurang menarik dan kurang diminati. Permainan ini belum memenuhi kriteria pada informasi edukasi dan tantangan terlalu mudah untuk mereka. Permainan Bajaj Keliling harus menjadi permainan yang berkualitas dan mampu bersaing di pasar, penulis juga berharap dapat menjadi pembuat game yang memiliki user experience yang baik. Oleh karena itu untuk keberhasilan permainan Bajaj Keliling, perlu dilakukan lagi evaluasi terhadap siswa SD dan SMP yaitu target kalangan dari permainan ini.

Penelitian ini bertujuan untuk melakukan evaluasi permainan Bajaj Keliling terhadap siswa SD dan SMP yaitu target kalangan dari permainan ini. Setelah dilakukan evaluasi user experience pada permainan Bajaj Keliling, maka akan dilakukan perancangan ulang berdasarkan rekomendasi evaluasi user experience pertama, lalu hasil perancangan ulang permainan Bajaj Keliling akan dievaluasi kembali untuk melihat apakah hasil rekomendasi dari hasil evaluasi pertama berhasil atau tidak.

Perancangan ulang permainan menggunakan Unity3D. Unity pada umumnya dikenal sebagai Unity3D. Unity adalah sebuah game engine yang berbasis cross-platform dan sebuah software yang terintegrasi untuk membuat game, arsitektur bangunan dan simulasi [5]. Unity juga dapat digunakan untuk game offline maupun game online. Sistem inti engine ini memiliki beberapa pilihan bahasa pemrograman, diantaranya C\#, Javascript, dan Boo.

\section{METODE PENELITIAN}

Metode yang digunakan pada penelitian ini adalah metode Design Sprint untuk perancangan ulang permainan yang memiliki beberapa tahapan yaitu understand, diverge, decide, prototype, dan validate, serta metode Game Experience Questionnaire (GEQ) sebagai instrumen penelitiannya yang digunakan untuk mengetahui user experience para pemain. Design Sprint merupakan metode yang digunakan untuk membangun build project dan prototype dalam waktu 5 hari [6]. Design Sprint merupakan sebuah metode untuk membangun konsep produk yang memiliki fokus dalam mendapatkan validasi untuk memaksimalkan peluang dengan membuat rancangan produk yang sesuai dengan kebutuhan pengguna [7]. Game Experience Questionnaire (GEQ) adalah metode untuk mengevaluasi pengalaman 
pengguna pada permainan secara reliable, valid, dan sensitif menggunakan skala likert dengan lima tingkat gradasi jawaban. Flowchart dari metodologi penelitian ini dapat dilihat pada gambar 3.

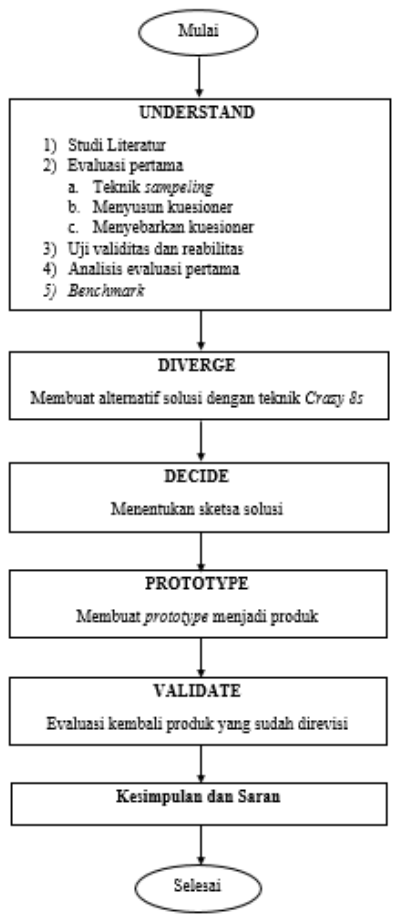

Gambar 3. Kerangka Metode Penelitian

\subsection{Understand}

Pada tahap understand, hal yang dilakukan adalah menggali informasi pada setiap komponen masalah secara menyeluruh agar dapat memahami permasalahan, teknik yang dapat digunakan adalah interview, survey, atau analisis. Tahap ini memiliki beberapa langkah yaitu melakukan studi literatur, dan melakukan evaluasi pertama pada game yang sudah ada. Tahap ini bertujuan untuk mengetahui karakteristik game lebih spesifik dan permasalahn yang ada pada game. Output pada langkah ini berupa metode yang digunakan, permasalahan, analisis hasil kuesioner, analisis evaluasi, dan benchmark.

1) Studi Literatur

Studi literatur yang dilakukan adalah melalui beberapa jurnal atau hasil penelitian dari beberapa ahli yang digunakan dalam menyelesaikan penelitian ini.

2) Evaluasi Game

Dalam mengevaluasi game, terdapat beberapa langkah. Dimulai dari menentukan populasi dan sampel, menyusun kuesioner, menyebarkan kuesioner, uji validitas dan reliabilitas, analisis evaluasi, dan benchmark.

a. Teknik Sampling : Dalam penelitian ini peneliti menggunakan teknik sampling non probability dengan teknik purposive sampling. Purposive sampling merupakan sebuah teknik pengumpulan sampel sumber data dengan pertimbangan tertentu [8]. Pada penelitian ini responden yang dibutuhkan sejumlah 30 orang. Adapun kriteria yang dijadikan sebagai sampel penelitian yaitu siswa SD hingga SMP dan siswa dengan umur minimal 10 tahun dan maksimal 15 tahun.

b. Menyusun Kuesioner : Pada langkah ini, kuesioner disusun berdasarkan metode evaluasi Game Experience Questionnaire (GEQ). Game Experience Questionnaire (GEQ) memiliki struktur yang modular, yang terdiri dari Core Module, In-game Module, Social Presence Module, dan Post Game Module [9].

- $\quad$ Core Module merupakan bagian inti dari GEQ. Modul ini terdiri dari 33 pertanyaan, dan dinilai berdasarkan 7 komponen yaitu immersion dalam permainan, alur dari permainan, kemampuan pengguna terhadap permainan, tensi dari permainan, tantangan yang dirasakan, serta efek negatif dan positif selama bermain. Modul ini berfungsi untuk mengetahui pengalaman responden saat memainkan game. 
- In-game Module merupakan versi pendek dari Core Module. Modul ini terdiri dari 14 pertanyaan, pertanyaan pada modul ini diambil dari 2 pertanyaan pada masing-masing komponen dari Core Module. Pada modul ini responden diminta untuk menghentikan permainan di tengah-tengah permainan untuk mengisi kuisioner. Modul ini berfungsi untuk mengetahui pengalaman responden saat diberhentikan saat sedang bermain game.

- Social Presence Module ini terdiri dari 17 pertanyaan, dan dinilai berdasarkan 3 komponen yaitu Psychological Involvement - Emphaty, Psychological Involvement - Negative Feelings dan Behavioural Involvement. Modul ini menginvestigasi tentang keterlibatan perilaku dan psikologi seorang pengguna terhadap pengguna lainnya. Pada penelitian ini Social Presence Module tidak digunakan karena permainan Bajaj Keliling bersifat single player.

- Post Game Module terdiri dari 17 pertanyaan menilai bagaimana perasaan setelah pemain selesai bermain, dan dinilai berdasarkan 4 komponen yaitu pengalaman positif, pengalaman negatif, kelelahan yang dirasakan dan returning to reality yang dirasakan pengguna setelah selesai bermain. Modul ini berfungsi untuk mengetahui pengalaman responden setelah selesai bermain game.

c. Menyebar Kuesioner : Penyebaran kuesioner dilakukan secara online melalui google form. Responden akan diberikan penjelasan mengenai maksud dan tujuan dari disebarkannya kuesioner. Selama pengisian kuesioner, responden akan didampingi secara synchronous.

d. Uji Validitas dan Reliabilitas : Setelah mendapatkan hasil kuesioner, langkah selanjutnya adalah melakukan pengujian validitas dan reliabilitas. Uji validitas bertujuan untuk mengukur valid atau tidaknya suatu instrumen yang digunakan pada penelitian, sedangkan uji reliabilitas digunakan untuk mengetahui tingkat konsistensi jawaban oleh responden.

e. Analisis Evaluasi : Analisis evaluasi dilakukan untuk mendapatkan hasil karakteristik responden yaitu mengenai usia dan berapa lama waktu yang dihabiskan responden untuk bermain game.

f. Benchmark: Hasil pengolahan data dipetakan ke dalam bentuk diagram atau tabel. Langkah ini bertujuan untuk mengetahui perbaikan dari game yang dievaluasi dan membandingkan antara produk yang ada saat ini dan produk rekomendasi yang dirancang.

\subsection{Diverge}

Pada tahap ini, hal yang dilakukan adalah brainstorming dengan cara membuat ide-ide untuk solusi permasalahan yang diketahui pada tahap understand. Pada tahap ini, teknik yang digunakan adalah Crazy $8 s$ untuk menulis ide yang bisa mengatasi permasalahan. Crazy $8 s$ adalah teknik membuat solusi dan menggambarnya dalam bentuk sketsa sebanyak 8 alternatif pada kertas.

\subsection{Decide}

Pada tahap ini, hal yang dilakukan adalah menentukan sketsa mana yang yang mampu menyelesaikan permasalahan dan dapat diimplementasikan. Untuk memilih salah satu ide yang dianggap baik, maka teknik supervote digunakan pada tahap ini. Supervote diambil dari 50\% dari responden, yaitu 15 orang.

\subsection{Prototype}

Pada tahap ini akan dibuat rancangan nyata dari storyboard yang telah terpilih menggunakan Unity3D dan Adobe Illustrator CS6.

\subsection{Validate}

Setelah selesai membuat prototype, maka perlu dilakukan kembali evaluasi hasil rancangan ulang pada permainan. Pada tahap ini, hal yang dilakukan adalah memvalidasi kembali kepada pengguna produk menggunakan teknik small data yaitu dengan melakukan penyebaran kuesioner GEQ dan pengolahan data seperti pada tahap understand kepada beberapa responden yang dipilih. Tahap ini bertujuan mengukur apakah rancangan baru meningkat atau tidak. Hasil analisis pada tahap ini akan dibandingkan dengan hasil analisis pada tahap understand atau evaluasi pertama.

\section{HASIL ANALISIS DAN PEMBAHASAN}

\subsection{Understand}
1) Evaluasi Game 
Pada tahap ini dilakukan penelitian berupa analisis menggunakan data-data dan pengujian untuk mengetahui lebih spesifik permasalahan pada permainan.

a. Uji Validitas dan Reliabilitas

- Uji Validitas

Nilai $r$ tabel dengan $\mathrm{N}=30$ dan signifikansi sebesar 5\% ditemukan nilai $\mathrm{r}$ tabel sebesar 0.3610 . Instrumen dikatakan valid jika korelasi ( $r$ hitung) lebih besar dari $r$ tabel dengan $\alpha 0,05$. Hasil uji validitas pada seluruh modul GEQ membuktikan bahwa seluruh pernyataan memiliki nilai $r$ hitung > $\mathrm{r}$ tabel sehingga dapat dinyatakan bahwa seluruh pernyataan yang ada pada seluruh modul GEQ valid. Berikut hasil uji validitas pada tabel 1.

Tabel 1. Hasil Uji Validitas

\begin{tabular}{clc}
\hline No & \multicolumn{1}{c}{ Modul } & Keterangan \\
\hline 1 & Core Module & Valid \\
2 & In-game Module & Valid \\
3 & Post Game Module & Valid \\
\hline
\end{tabular}

Kesimpulannya, semua instrumen pada Core Module, In-game Module, dan Post Game Module dapat digunakan pada penelitian.

- Uji Reliabilitas

Cronbach's Alpha merupakan salah satu koefisien reliabilitas yang paling sering digunakan. Skala pengukuran yang reliabel sebaiknya memiliki nilai $\alpha$ minimal 0,7 [10]. Kuesioner dapat dikatakan reliabel jika memiliki nilai $\alpha \geq 0,7$ atau mendekati 1 . Hasil uji reliabilitas pada seluruh modul GEQ membuktikan bahwa seluruh komponen memiliki nilai Cronbach's Alpha lebih dari 0,7 sehingga dapat dinyatakan bahwa seluruh komponen reliabel. Berikut hasil uji reliabilitas pada tabel 2.

Tabel 2. Hasil Uji Reliabilitas

\begin{tabular}{clc}
\hline No & \multicolumn{1}{c}{ Modul } & Keterangan \\
\hline 1 & Core Module & Reliabel \\
2 & In-game Module & Reliabel \\
3 & Post Game Module & Reliabel \\
\hline
\end{tabular}

b. Analisis Evaluasi

Responden yang paling tinggi adalah usia 15 tahun dengan persentase $40 \%$ sedangkan yang paling sedikit adalah usia 10 tahun dengan persentase $6,7 \%$. Untuk lebih jelasnya dapat dilihat pada gambar 4. Waktu bermain yang paling tinggi adalah 2 jam dengan persentase 43,3\% sedangkan yang paling rendah adalah 3 jam dengan persentase $26,7 \%$. Untuk lebih jelasnya dapat dilihat pada gambar 5 .

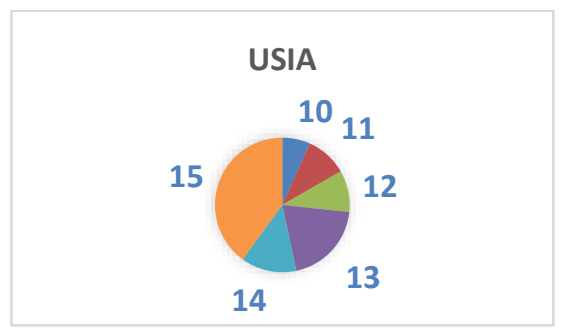

Gambar 4. Berdasarkan Usia

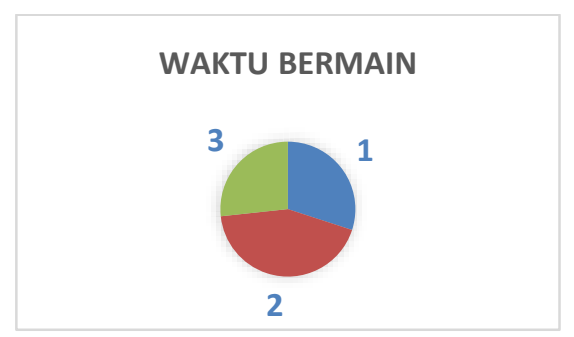

Gambar 5. Berdasarkan Waktu Bermain

c. Benchmark

Untuk mengetahui permasalahan yang ada berdasarkan data kuesioner yang telah diperoleh maka akan dibuat benchmark dengan menggunakan tabulasi hasil kuesioner. Adapun tujuan dari benchmark untuk mengukur keberhasilan permainan saat ini dan rancangan ulang yang akan dibuat pada tahap prototype.

- Core Module

Komponen Negative Affect dan Tension memiliki nilai yang rendah karena komponen tersebut memang akan semakin baik jika nilainya semakin rendah. Ini menunjukkan bahwa responden tidak 
merasa kesal atau marah saat bermain, serta permainan tidak membuat suasana hati responden buruk saat bermain.

Komponen yang memiliki nilai rendah lainnya adalah Flow dan Challenge, ini menunjukkan kebanyakan responden tidak mengalami kepuasan saat bermain pada aspek tantangan, karena tantangan terlalu mudah sehingga berpengaruh pada komponen Flow yang menunjukkan pemain tidak sepenuhnya fokus dan terbawa/tenggelam ke dunia permainan karena tantangan terlalu mudah.

Pada komponen Competence, Immersion, dan Positive Affect menunjukkan hasil di atas ratarata, ini menunjukkan bahwa kebanyakan responden merasa terampil dan pandai memainkan permainan, responden tertarik dan menyukai estetika permainan, serta responden tidak menunjukkan suasana hati yang buruk dan merasa senang saat bermain.

Tabel 3. Mean dan SD pada Core Module

\begin{tabular}{clcc}
\hline No & \multicolumn{1}{c}{ Komponen } & Mean & SD \\
\hline 1 & Competence & 4,35 & 0,37 \\
2 & Immersion & 3,80 & 0,27 \\
3 & Flow & 2,17 & 0,51 \\
4 & Tension/Annoyance & 2,07 & 0,25 \\
5 & Challenge & 2,21 & 0,49 \\
6 & Negative Affect & 2,38 & 0,43 \\
7 & Positive Affect & 4,06 & 0,25 \\
\hline
\end{tabular}

- $\quad$ In-game Module

Komponen pada modul ini tidak berbeda dengan Core Module. Komponen Negative Affect dan Tension memiliki nilai yang rendah karena komponen tersebut memang akan semakin baik jika nilainya semakin rendah. Ini menunjukkan bahwa responden tidak merasa kesal atau marah saat bermain, serta permainan tidak membuat suasana hati responden buruk saat bermain.

Komponen yang memiliki nilai rendah lainnya adalah Challenge, ini menunjukkan kebanyakan responden tidak mengalami kepuasan saat bermain pada aspek tantangan, permainan ini memiliki tantangan yang mudah sehingga responden tidak merasakan perlawanan.

Pada komponen Competence, Immersion, Flow dan Positive Affect menunjukkan hasil di atas rata-rata, ini menunjukkan bahwa kebanyakan responden merasa terampil dan pandai memainkan permainan, responden tertarik dan menyukai estetika permainan, responden berkonsentrasi di tengah permainan, serta responden tidak menunjukkan suasana hati yang buruk dan merasa senang saat bermain.

Tabel 4. Mean dan SD pada In-game Module

\begin{tabular}{clcc}
\hline No & Komponen & Mean & SD \\
\hline 1 & Competence & 4,43 & 0,45 \\
2 & Immersion & 3,95 & 0,20 \\
3 & Flow & 3,20 & 0,47 \\
4 & Tension/Annoyance & 1,97 & 0,32 \\
5 & Challenge & 2,22 & 0,55 \\
6 & Negative Affect & 2,32 & 0,43 \\
7 & Positive Affect & 4,02 & 0,38 \\
\hline
\end{tabular}

\section{- $\quad$ Post Game Module}

Pada modul ini, komponen Negative Experience dan Tiredness memiliki nilai yang rendah karena komponen tersebut memang akan semakin baik jika nilainya semakin rendah. Ini menunjukkan bahwa responden tidak merasa buruk atau menyesal setelah selesai bermain game, serta responden tidak merasa letih atau kelelahan setelah selesai bermain.

Pada komponen Positive Experience dan Returning to Reality, kedua memiliki hasil di atas ratarata. Ini menunjukkan bahwa responden bangga dan kuat saat selesai bermain, serta responden tidak merasa bingung dan mudah untuk kembali ke kenyataan.

Komponen Returning to Reality menilai seberapa banyak pengalaman bermain yang masih bisa dirasakan atau diingat oleh pemain setelah mereka selesai bermain. Tingginya nilai pada komponen ini merupakan dampak langsung dari tingginya nilai komponen Immersion pada permainan. Pemain 
baru tidak mudah untuk melupakan pengalaman bermain yang dialaminya karena pengalaman tersebut menarik atau menyenangkan bagi mereka untuk diingat.

Tabel 5. Mean dan SD pada Post Game Module

\begin{tabular}{clcc}
\hline No & \multicolumn{1}{c}{ Komponen } & Mean & SD \\
\hline 1 & Positive Experience & 4,03 & 0,26 \\
2 & Negative Experience & 2,04 & 0,24 \\
3 & Tiredness & 2,13 & 0,35 \\
4 & Returning to Reality & 3,18 & 0,36 \\
\hline
\end{tabular}

Berdasarkan penjelasan di atas, ada dua komponen yang memiliki nilai mean rendah yaitu komponen Flow pada Core Module dan komponen Challenge pada Core Module dan In-game Module yang artinya memiliki potensi untuk diperbaiki. Kedua komponen tersebut berkaitan, jika game terlalu mudah maka pemain akan sulit untuk terbawa tenggelam kedalam permainan.

\subsection{Diverge}

Pada tahap ini dilakukan pembuatan sketsa berdasarkan permasalahan yang muncul di tahap sebelumnya. Berdasarkan tahap sebelumnya, komponen yang bernilai di bawah standar yaitu komponen Flow dan Challenge, maka diperlukan solusi untuk perbaikan pada hal tersebut. Pada tahap ini digunakan Crazy $8 s$ untuk menggambarkan ide sketsa yang bisa mengatasi permasalahan. Berikut tabel 6 adalah tabel solusi yang akan dibuat.

Tabel 6. Solusi

\begin{tabular}{|c|l|l|}
\hline No & Komponen & \multicolumn{1}{|c|}{ Solusi } \\
\hline 1 & Flow & Mengganti fitur stage menjadi level \\
\hline 2 & Challenge & Menambah tantangan baru berupa pertanyaan setiap ingin memulai pertandingan \\
\hline
\end{tabular}

Adapun sketsa yang dibuat pada tahap ini berkaitan dengan solusi yaitu fitur level dan penambahan tantangan berupa pertanyaan. Berikut adalah hasil sketsa yang terdiri dari 8 ide solusi menggunakan teknik Crazy $8 s$.

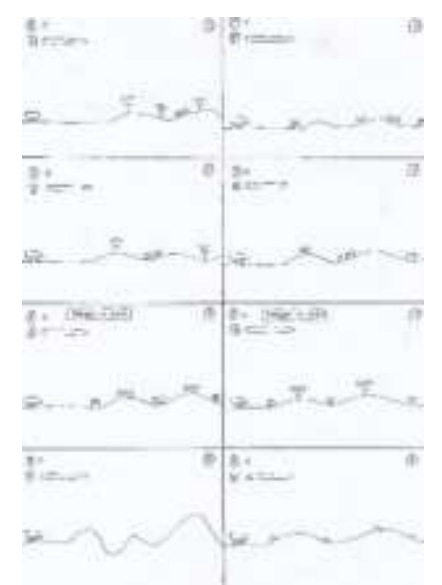

Gambar 6. Hasil Sketsa Fitur Level

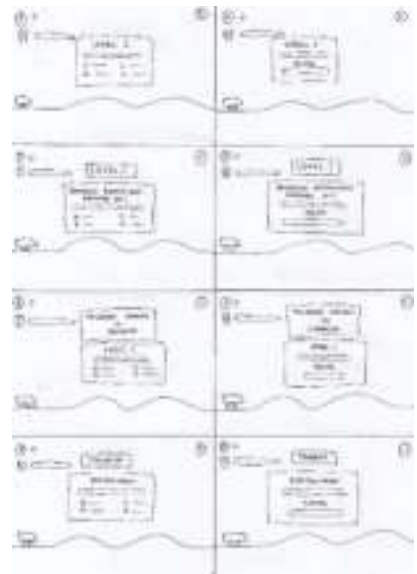

Gambar 7. Hasil Sketsa Penambahan Tantangan

\subsection{Decide}

Teknik yang digunakan untuk menentukan ide sketsa adalah supervote. Pada teknik ini akan dipilih secara acak $50 \%$ dari jumlah responden, yaitu 15 orang untuk memilih satu sketsa dari delapan sketsa alternatif. Lalu responden akan memilih salah satu dadiri delapan sketsa yang menarik. Setelah dilakukan pemilihan sketsa kepada 15 orang responden, maka diperoleh hasil pada tabel 7.

Tabel 7. Hasil Supervote

\begin{tabular}{|c|l|c|c|c|c|c|c|c|c|}
\hline \multirow{2}{*}{ No } & \multirow{2}{*}{ Fitur } & \multicolumn{1}{|c|}{ Ide Ke- } \\
\cline { 3 - 12 } & & A & B & C & D & E & F & G & H \\
\hline 1 & Fitur Level & 0 & 2 & 1 & 9 & 2 & 1 & 0 & 0 \\
\hline 2 & Penambahan Tantangan & 1 & 0 & 2 & 1 & 8 & 1 & 2 & 0 \\
\hline
\end{tabular}

1) Fitur Level

Pada tabel 7 menunjukkan bahwa ide D memiliki total suara sebanyak 9. Ide ini terpilih karena tantangannya berupa posisi bensin yang semakin berjarak jauh dan persediaannya yang berkurang. Berikut adalah hasil storyboard pada sketsa D. 


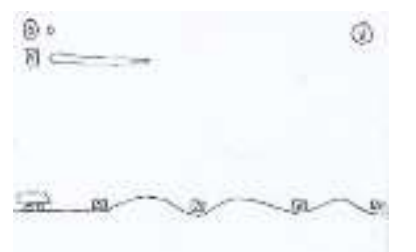

Gambar 8. Storyboard Fitur Level 1

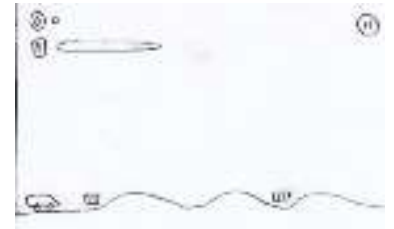

Gambar 9. Storyboard Fitur Level 2

Storyboard pada gambar 8 merupakan gambaran level awal, bensin belum berjarak jauh dan persediaan bensin belum langka, sehingga pemain masih belum terlalu sulit untuk bertahan. Storyboard pada gambar 9 merupakan gambaran level selanjutnya, bensin sudah berjarak jauh dan persediaan sudah langka, sehingga pemain semakin lama semakin merasa sulit untuk bertahan.

2) Penambahan Tantangan

Pada tabel 7 menunjukkan bahwa ide E memiliki total suara sebanyak 8. Ide ini terpilih karena tampilan pada ide ini lebih ramah karena adanya ucapan 'Selamat Datang di Jakarta' dibandingkan ide lain, lalu tipe jawaban merupakan pilihan berganda yang mana lebih mudah untuk langsung memilih jawaban dibandingkan mengetik jawaban pada kolom. Berikut adalah hasil dari storyboard sketsa E.

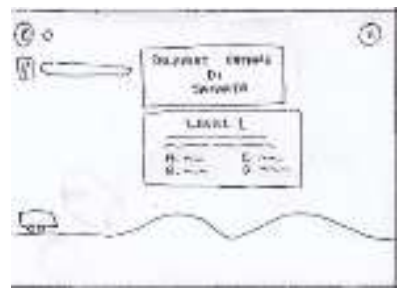

Gambar 10. Fitur Pertanyaan

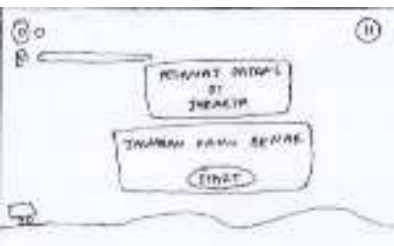

Gambar 11. Jawaban Benar

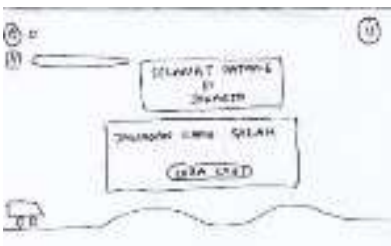

Gambar 12. Jawaban Salah

Storyboard pada gambar 10 merupakan gambaran pada awal permainan setiap level, pemain harus menjawab pertanyaan yang ada dengan benar, sehingga dapat memulai permainan. Storyboard pada gambar 11 merupakan gambaran ketika pemain menjawab pertanyaan dengan benar, pemain harus menekan tombol 'Start' untuk memulai permainan. Storyboard pada gambar 12 merupakan gambaran ketika pemain salah dalam menjawab pertanyaan, pemain harus menekan tombol 'Back' untuk kembali ke pertanyaan dan harus menjawab pertanyaan dengan benar.

\subsection{Prototype}

Pada langkah ini akan dibuat prototype sesuai dengan storyboard pada langkah sebelumnya. Prototype dalam bentuk nyata dibuat dengan menggunakan perangkat lunak Unity 3D.

1) Implementasi Fitur Level

Setelah dilakukan evaluasi permainan kepada responden, maka pemilihan untuk fitur level akan diimplementasikan.

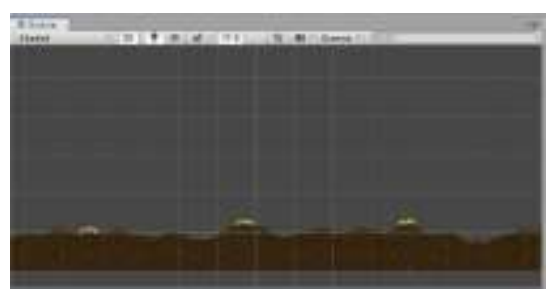

Gambar 13. Layout Fitur Bensin

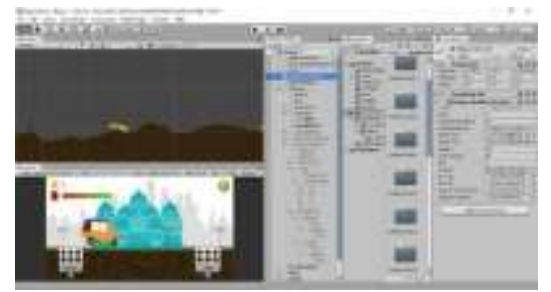

Gambar 14. Proses Implementasi Fitur Level

2) Implementasi Penambahan Tantangan

Setelah dilakukan evaluasi permainan kepada responden, maka pemilihan untuk penambahan tantangan berupa pertanyaan setiap memasuki level akan diimplementasikan. 


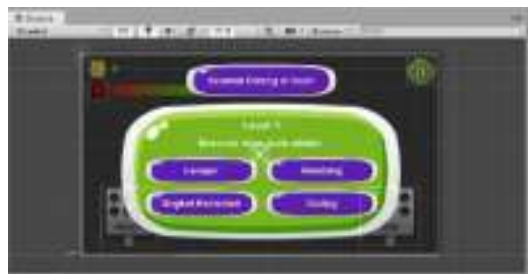

Gambar 15. Layout Fitur Pertanyaan

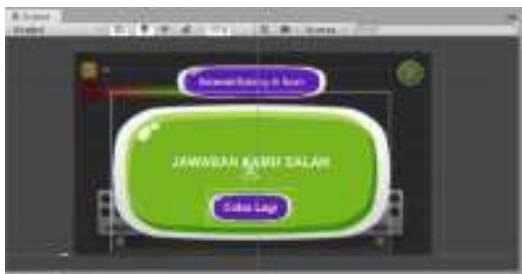

Gambar 17. Layout Jawaban Salah

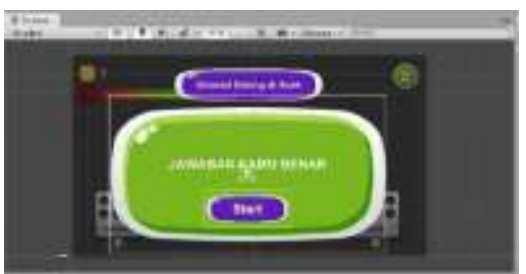

Gambar 16. Layout Jawaban Benar

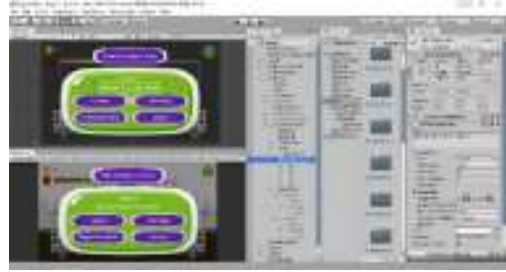

Gambar 18. Implementasi Fitur Pertanyaan

\subsection{Validate}

Pada tahap validasi ini menggunakan teknik small data yaitu dengan menyebar kuesioner kepada responden dengan jumlah sampel sebanyak 15 orang. Tujuan evaluasi akhir ini untuk mengukur apakah rancangan ulang yang sudah dibuat sudah mengatasi masalah atau tidak.

1) Uji Validitas dan Reliabilitas

- Uji Validitas

Nilai $\mathrm{r}$ tabel dengan $\mathrm{N}=15$ dan signifikansi sebesar 5\% ditemukan nilai $\mathrm{r}$ tabel sebesar 0.5140. Instrumen dikatakan valid jika korelasi ( $\mathrm{r}$ hitung) lebih besar dari $\mathrm{r}$ tabel dengan $\alpha 0,05$. Hasil uji validitas pada seluruh modul GEQ membuktikan bahwa seluruh pernyataan memiliki nilai $r$ hitung $>r$ tabel sehingga dapat dinyatakan bahwa seluruh pernyataan valid. Berikut hasil uji validitas pada tabel 8.

Tabel 8. Hasil Uji Validitas 2

\begin{tabular}{clc}
\hline No & \multicolumn{1}{c}{ Modul } & Keterangan \\
\hline 1 & Core Module & Valid \\
2 & In-game Module & Valid \\
3 & Post Game Module & Valid \\
\hline
\end{tabular}

- Uji Reliabilitas

Kuesioner dapat dikatakan reliabel jika memiliki nilai $\alpha \geq 0,7$ atau mendekati 1 . Hasil uji reliabilitas pada seluruh modul GEQ membuktikan bahwa seluruh komponen memiliki nilai Cronbach's Alpha lebih dari 0,7 sehingga dapat dinyatakan bahwa seluruh komponen reliabel. Berikut hasil uji reliabilitas pada tabel 9.

Tabel 9. Hasil Uji Reliabilitas 2

\begin{tabular}{clc}
\hline No & \multicolumn{1}{c}{ Modul } & Keterangan \\
\hline 1 & Core Module & Reliabel \\
2 & In-game Module & Reliabel \\
3 & Post Game Module & Reliabel \\
\hline
\end{tabular}

2) Benchmark

Berikut adalah tabel hasil rata-rata keseluruhan sebelum dilakukan implementasi dan sesudah dilakukan implementasi.

Tabel 10. Tabel Hasil Evaluasi Akhir Core Module

\begin{tabular}{|c|l|c|c|c|c|}
\hline \multirow{2}{*}{ No } & \multirow{2}{*}{ Komponen } & \multicolumn{2}{|c|}{ Mean } & \multirow{2}{*}{ Selisih } & \multirow{2}{*}{ Keterangan } \\
\cline { 3 - 4 } & & Sebelum & Sesudah & & \\
\hline 1 & Competence & 4,35 & 4,39 & 0,04 & Meningkat \\
\hline 2 & Immersion & 3,80 & 4,26 & 0,46 & Meningkat \\
\hline 3 & Flow & 2,17 & 3,17 & 1,00 & Meningkat \\
\hline 4 & Tension/Annoyance & 2,07 & 2,07 & 0 & Stabil \\
\hline 5 & Challenge & 2,21 & 3,09 & 0,88 & Meningkat \\
\hline
\end{tabular}




\begin{tabular}{|c|l|c|c|c|c|}
\hline 6 & Negative Affect & 2,38 & 2,25 & 0,13 & Menurun \\
\hline 7 & Positive Affect & 4,06 & 4,20 & 0,14 & Meningkat \\
\hline
\end{tabular}

Tabel 11. Tabel Hasil Evaluasi Akhir In-game Module

\begin{tabular}{|c|l|c|c|c|c|}
\hline \multirow{2}{*}{ No } & \multirow{2}{*}{ Komponen } & \multicolumn{2}{|c|}{ Mean } & \multirow{2}{*}{ Selisih } & \multirow{2}{*}{ Keterangan } \\
\cline { 3 - 4 } & & Sebelum & Sesudah & & \\
\hline 1 & Competence & 4,43 & 4,47 & 0,04 & Meningkat \\
\hline 2 & Immersion & 3,95 & 4,47 & 0,52 & Meningkat \\
\hline 3 & Flow & 3,20 & 3,43 & 0,23 & Meningkat \\
\hline 4 & Tension/Annoyance & 1,97 & 2,00 & 0,03 & Meningkat \\
\hline 5 & Challenge & 2,22 & 2,37 & 0,15 & Meningkat \\
\hline 6 & Negative Affect & 2,32 & 1,97 & 0,35 & Menurun \\
\hline 7 & Positive Affect & 4,02 & 4,17 & 0,15 & Meningkat \\
\hline
\end{tabular}

Tabel 12. Tabel Hasil Evaluasi Akhir Post Game Module

\begin{tabular}{|c|l|c|c|c|c|}
\hline \multirow{2}{*}{ No } & \multirow{2}{*}{ Komponen } & \multicolumn{2}{|c|}{ Mean } & \multirow{2}{*}{ Selisih } & \multirow{2}{*}{ Keterangan } \\
\cline { 3 - 4 } & & Sebelum & Sesudah & & \\
\hline 1 & Positive Experience & 4,03 & 4,11 & 0,08 & Meningkat \\
\hline 2 & Negative Experience & 2,04 & 1,79 & 0,25 & Menurun \\
\hline 3 & Tiredness & 2,13 & 2,20 & 0,07 & Meningkat \\
\hline 4 & Returning to Reality & 3,18 & 3,78 & 0,60 & Meningkat \\
\hline
\end{tabular}

Dari tabel di atas dapat diketahui bahwa nilai rata-rata untuk komponen Flow dan Challenge mengalami peningkatan. Perlu juga dilihat bahwa komponen Tension/Annoyance pada In-game Module dan komponen Tiredness pada Post Game Module juga mengalami peningkatan karena pengaruh dari peningkatan pada komponen Challenge. Hal tersebut membuat pemain lebih merasa kesulitan dan mudah lelah karena tantangan.

Pada Core Module, komponen Flow mengalami peningkatan sebesar 1 dari 2.17 menjadi 3.17 hasil rata-rata tersebut berada di atas median, komponen Challenge mengalami peningkatan 0.88 dari 2.21 menjadi 3.09 hasil rata-rata tersebut berada di atas median. Pada In-game Module, komponen Challenge mengalami peningkatan 0.15 dari 2.22 menjadi 2.37 namun hasil rata-rata tersebut masih berada di bawah median.

\section{KESIMPULAN}

Berdasarkan dari evaluasi pertama permainan Bajaj Keliling pada tahap understand diperoleh hasil pengolahan data menunjukkan nilai rata-rata yang rendah merupakan komponen Flow pada Core Module dan komponen Challenge pada Core Module dan Post Game Module. Faktor terjadinya hasil nilai rendah pada komponen Challenge adalah tantangan pada permainan ini terlalu mudah, fitur stage memiliki tantangan yang selalu sama dan monoton, sehingga berpengaruh pada komponen Flow yang membuat pemain tidak fokus dan tidak tenggelam ke permainan, serta membuat pemain mudah bosan dengan permainan.

Telah dilakukan perbaikan untuk perancangan ulang berdasarkan tahapan-tahapan pada metode Design Sprint. Oleh karena hasil komponen Flow dan Challenge bernilai rendah akibat tantangan pada stage terlalu mudah dan monoton, maka perbaikan berupa perubahan fitur stage menjadi level dengan cara mengubah posisi bensin menjadi lebih berjarak jauh dan mengurangi persediaan bensin setiap level meningkat dan penambahan tantangan berupa pertanyaan setiap memulai permainan pada setiap level.

Berdasarkan hasil evaluasi akhir pada permainan Bajaj Keliling yang telah dilakukan perbaikan berdasarkan evaluasi pertama, maka diperoleh hasil bahwa pada komponen Flow dan Challenge telah berhasil mengalami peningkatan karena fitur level dan penambahan tantangan berupa pertanyaan setiap memulai permainan pada setiap level. Peningkatan pada komponen Challenge juga berpengaruh pada peningkatan komponen Tension/Annoyance dan Tiredness. Hal tersebut membuat pemain lebih merasa kesulitan dan mudah lelah karena tantangan. Hasil komponen Flow dan Challenge pada Core Module meningkat dan memiliki nilai rata-rata di atas median. Hasil dari komponen Challenge pada In-game Module juga meningkat namun nilai rata-rata masih di bawah median.

Pada penelitian selanjutnya diharapkan dapat mengambil sampel yang lebih spesifik lagi dengan menentukan responden yang menyukai bermain game atau tidak. Pada penelitian selanjutnya dapat dikembangkan dengan menambahkan pemilihan karakter dengan menambahkan warna dan bentuk karakter bajaj.

\section{DAFTAR PUSTAKA}

[1] Henry, S. 2010 Cerdas dengan Game: Panduan Praktis Bagi Orangtua dalam Mendampingi Anak Bermain Game. PT. Gramedia Pustaka Utama: Jakarta. 
[2] Fullerton, T. 2008. Game Design Workshop: A Playcentric Approach to Creating Innovative Games. Burlington: Morgan Kaufmann. Adam, E. 2014. Fundamentals of Game Design Third Edition. United States of America: New Riders.

[3] Adam, E. 2014. Fundamentals of Game Design Third Edition. United States of America: New Riders.

[4] Gavin, M. dan David, S. 2007. Making User Experience a Business Strategy. Towards a UX Manifesto. 35-42.

[5] Haas, Jhon. 2002. A History of the unity game engine. Worcester Polytechnic Institute, diakses tanggal : 12 Juni 2019.

[6] Knapp, J.,Zeratsky, K., Kowitz, B. 2016. Sprint : How to Solve Big Problems and Test New Ideas in Just Five Days. New York : Simon \& Schuster.

[7] Banfield, R, Lombardo, C.T., \& Wax, T. 2015. Design Sprint : A Practical Guidebook for Building Great Digital Products. Sebastopol: O'Reilly Media, Inc.

[8] Sugiyono, S., \& Sutrisno, J. 2017. Model Imitasi Mahasiswa Dalam Proses Pembelajaran. Jurnal Penelitian Pendidikan, 9, 1, $1357-1362$.

[9] Ijsselsteijn, W.A., De K., Y.A.W. \& Poels, K. 2007. Game Experience Questionnaire. Eindhoven: Technische Universiteit Eindhoven.

[10] Uyanto, S. S., 2009. Pedoman Analisis Data dengan SPSS. 3rd penyunt. Yogyakarta: Graha Ilmu. 